\title{
Impact of Corona Pandemic on Numbers in Diagnostic Pathology; A Nationwide Survey in the Netherlands
}

Marie-Louise F van Velthuysen ( $\nabla$ m.vanvelthuysen@erasmusmc.nl )

https://orcid.org/0000-0003-0435-9494

\section{Susanne van Eeden}

Erasmus Medical Centre: Erasmus MC

\section{Saskia le Cessie}

Leiden University Medical Center: Leids Universitair Medisch Centrum

\section{Mirthe de Boer}

University Medical Center Utrecht

\section{Hester van Boven}

Netherlands Cancer Institute: Antoni van Leeuwenhoek Nederlands Kanker Instituut

\section{Bregje M Koomen}

University Medical Center Utrecht

\section{Frank Roozekrans}

Laboratorium Pathologie Oost Nederland

\section{Jos Bart}

University Medical Centre Groningen: Universitair Medisch Centrum Groningen

\section{Wim Timens}

University Medical Centre Groningen: Universitair Medisch Centrum Groningen

\section{Rinus JM Voorham}

PALGA

\section{Research article}

Keywords: COVID-19, Workload, Pathology, Malignancy rate, Cytopathology

Posted Date: June 30th, 2021

DOl: https://doi.org/10.21203/rs.3.rs-659196/v1

License: (c) (1) This work is licensed under a Creative Commons Attribution 4.0 International License. Read Full License 


\section{Abstract}

Background: The SARS-CoV-2 pandemic has a huge impact on healthcare provided. The nationwide pathology registry of the Netherlands, PALGA, offers an outstanding opportunity to measure this impact for diseases in which pathology examinations are involved.

Methods: Pathology specimen numbers in 2020 were compared with specimen numbers in 2019 for 5 periods of 4 weeks, representing two lockdowns and the periods in between, taking into account localization, procedure and dignity of diagnosis.

Results: The largest decrease was seen during the first lockdown (spring 2020), when numbers of pathology reports declined up to $88 \%$ and almost all specimen types were affected. Afterwards each specimen type showed its own dynamics with a decrease during the second lockdown for some, while for others numbers remained relatively low during the whole year. Generally, for most tissue types resections, cytology and malignant diagnoses showed less decrease than biopsies and benign diagnoses. A significant but small catch-up (up to 17\%) was only seen for benign resections of the lower gastrointestinal tract, malignant skin resections and gallbladder resections.

Conclusion: The corona pandemic has a significant effect on pathology diagnostics. This effect was most pronounced during the first lockdown, diverse for different sites of origin and for cytology compared with histology. The data presented here can help to assess the consequences on (public) health and provide a starting point in the discussion on how to make the best choices in times of scarce healthcare resources, considering the impact of both benign and malignant disease on quality of life.

\section{Introduction}

During the first spike of the SARS-CoV-2 pandemic extensive numbers of covid-19 patients put an enormous strain on healthcare services worldwide. In ensuring enough hospital capacity for severely ill covid-19 patients less urgent medical treatment was often put on hold. Moreover, patients avoided or delayed seeking care for other health issues [1] .

While medical staff working in the frontline were stretched to their limits, the workload for some other healthcare workers diminished. Among them were pathologists who received less specimens than usual, especially during lockdown $[2,3]$.

At first glance this might just seem an obvious consequence of the situation, but investigating the reduced diagnostic volume in detail may provide important insights. The number and kind of specimens received in pathology laboratories reflect an important part of patientcare given, so taking stock of the diagnostic workload for pathologists may help understand what happened clinically. Identifying the most affected areas in pathology may reveal healthcare choices that were either implicitly or explicitly made during the crisis and may be a good starting point for evaluating their long-term effects. 
The Netherlands is a country particularly suitable to study how the diagnostic volume in pathology laboratories changed during the corona pandemic, because it has a nationwide database named PALGA (Pathologisch Anatomisch Landelijk Geautomatiseerd Archief), which registers all pathology reports since 1991[4].

By making use of the PALGA database this study assesses the changes in specimen numbers for the different areas in pathology throughout 2020 , not only covering the first spike of the SARS-CoV-2 pandemic in spring 2020, but also the periods after the first lockdown and the second spike in autumn. It is evaluated whether and how numbers decreased, whether and how quickly decreased numbers returned to normal and whether any catching up was seen.

\section{Materials And Methods}

\section{Corona in the Netherlands}

The first Dutch covid-19 patient was officially diagnosed on February 27th 2020. In early March the first corona-related death was reported and in the following weeks the number of covid-19 patients increased rapidly. [https://www.rivm.nl/coronavirus-covid-19/grafieken]

The government announced progressively strict measures to control the virus outbreak, resulting in an 'intelligent lockdown' from March 16th to June 1st. People were allowed to leave their houses, but the lockdown rules were aimed at minimising social interaction. For example, schools, universities, gyms, restaurants, pubs, theatres and museums were closed, events were cancelled, people were urged to work from home, to avoid contact with others and not to use public transport unless absolutely necessary.

Hospitals had to postpone much of the non-urgent medical care to cope with the increasing numbers of covid-19 patients. Doctors restricted the number of actual patient visits by implementing telemedicine (phone calls, video consulting) as much as possible. The Department of Health decided to pause the Dutch population screening programmes for colorectal carcinoma, breast carcinoma and cervical carcinoma from March 16th to relieve the pressure on healthcare services. Screening for these malignancies was gradually resumed in the second half of May, the second half of June and July respectively.

On June 1st the lockdown measures were lifted until the second spike of the SARS-CoV-2 pandemic announced itself with a rapid increase in the number of covid-19 cases from September onwards. On October 14th the government reintroduced measures similar to those of the first lockdown, although schools remained open. This changed on December 16th when more restrictions were imposed: schools and non-essential shops had to close, resulting in a strict lockdown.

While healthcare services intended to continue non-covid patientcare as much as possible during this period, the increasing number of covid-19 patients and the drop-out of healthcare workers forced hospitals to downscale regular patientcare, although not as much as in spring. 


\section{Data from the PALGA database and statistics}

In the Netherlands a nationwide database named PALGA (Pathologisch Anatomisch Landelijk Geautomatiseerd Archief) records all pathology reports since 1991, which are coded by localisation (organ, body part or tissue type), procedure and diagnosis.

(https://www.palga.nl/en/assets/uploads/Stichting/palga_artikel_2007.pdf).

Weekly case numbers of histological and cytological specimens from 2015-2020 were retrieved from the PALGA database, grouped by anatomical site, together with data on procedure (biopsy, resection) and dignity (benign, malignant) of the diagnosis.

The analyses on biopsies and resections contained lower specimen numbers than the total number of cases, because cases seen for revision or in consultation (and thus reported at least twice by different pathology laboratories) were not included.

For analyses on benign versus malignant not only cases seen for revision or in consultation were excluded, but also cases difficult to classify as benign or malignant, such as dysplasia, inadequate material and uncertain diagnosis. In cervical cytology all high risk HPV positive cases were regarded as 'malignancy'.

\section{Statistical analysis}

To calculate the expected numbers for 2020 per week, the average specimen numbers per week in the period 2015-2019 were calculated. To allow corrections for changing trends over the years, actual specimen numbers for week 2-10 of 2020 (pre-corona) were measured. The numbers for week 2-10 of 2020 were divided by the average numbers for week 2-10 of the 2015-2019 period. This factor was used to predict the numbers for the other weeks of 2020 (expected numbers).

To examine the impact of the governmental measures against the coronavirus on diagnostic volume in 2020, specimen numbers per week were calculated in five periods of four weeks (Table 1). Period 1 is week 13-16 in 2020 (March 23rd - April 19th) during the first lockdown. 
Table 1

Periods used to measure effect of pandemic; dates specified for 2020

\begin{tabular}{|c|c|c|}
\hline Period 1 & W13-W16 & $\begin{array}{l}\text { 2020: } 23 / 3-19 / 41 \text { st lockdown and Easter } \\
\text { 2019: } 25 / 3-21 / 4\end{array}$ \\
\hline Period 2 & W23-W26 & $\begin{array}{l}\text { 2020: 1/6-28/6 after } 1 \text { st lockdown and Pentecost } \\
\text { 2019: 3/6-30/6 Pentecost }\end{array}$ \\
\hline Period 3 & w33-w36 & $\begin{array}{l}\text { 2020: } 10 / 8-6 / 9 \\
\text { 2019: } 12 / 8-8 / 9\end{array}$ \\
\hline Period 4 & W43-W46 & $\begin{array}{l}\text { 2020: } 19 / 10-15 / 11 \text { start } 2 \text { nd lockdown } \\
\text { 2019: } 21 / 10-17 / 11\end{array}$ \\
\hline Period 5 & W47-W50 & $\begin{array}{l}\text { 2020: 16/11-13/12 2nd lockdown } \\
\text { 2019: 18/11-15/12 }\end{array}$ \\
\hline
\end{tabular}

To establish whether numbers of pathology specimens in 2020 were different from those in previous years and to establish whether this correlated with the measures against the SARS-CoV-2 pandemic, the following strategies were followed:

1. The total numbers observed per week in 2020 (M) were compared to the expected numbers according to localisation. The confidence interval $(\mathrm{Cl})$ of the measured number $(\mathrm{M})$ was calculated as $\mathrm{M}-1.96 \sqrt{M} ; \mathrm{M}+1.96 \sqrt{M}$ assuming that $\mathrm{M}$ followed a Poisson distribution. The observed numbers with $\mathrm{Cl}$ were divided by the expected number to obtain the ratio of observed versus expected.

2. To compare numbers in subgroups by procedure (biopsy, resection) and by dignity of diagnosis (benign, malignant) the numbers measured in $2020\left(\mathrm{M}_{20}\right)$ were compared with the numbers measured in $2019\left(\mathrm{M}_{19}\right)$. The $\mathrm{Cl}$ of this ratio was calculated, using that the standard error of a ratio of two Poisson distributed count variables is approximately equal to $\sqrt{\frac{M_{20}}{M_{19}{ }^{2}}+\frac{M_{20}{ }^{2}}{M_{19}{ }^{3}}}$

The numbers measured in 2020 were considered to deviate significantly if the $95 \%$ confidence interval of the calculated ratios did not contain $100 \%$. Ratios of less than $85 \%$ or more than $115 \%$, if not significantly different, are highlighted as possibly clinically significant[5]. Analyses were not performed if there were less than 20 cases per week.

\section{Results}

\section{General}


Based on the data from previous years (2015-2019) the expected diagnostic workload for all Dutch pathology laboratories in 2020 was a total number of 2,975,469 cases. However, pathologists received only $82 \%$ of the expected number $(2,427,960$ cases). The sharpest drop was observed in period 1 during the first lockdown in spring: the number of reported specimens $(78,465)$ was only $33 \%$ of the expected number $(236,789)$.

For histological specimens expected versus measured numbers for 2020 were 1,895,580 versus $1,633,804$ (86\%); for cytology expected versus measured numbers were 196,619 versus $178,180(90,63 \%)$ for cervical cytology specimens expected versus measured numbers were 883,261 versus 615,976 (70\%).

\section{Cytology}

Table 2 shows that in 2020 the relative decrease in numbers was most severe during the first lockdown, period 1 (week 13- week 16) in particular for specimens from cervix and breast (12\% and $35 \%$ of expected respectively), for which national screening programmes were put on hold. In period 1 all areas of cytology showed a lockdown dip, with the most modest dip for pancreas cytology, where the number of examined specimens remained within the expected range (Table 2).

\section{Table 2. Expected versus measured numbers of cytology examinations per week according to tissue type during the 5 periods examined.}

\begin{tabular}{|l||c|c||cc|c|c|c|}
\hline \multicolumn{1}{l||}{ Tissue type } & expected & measured & meas/exp & meas/exp & meas/exp & meas/exp & meas/exp \\
\hline Breast* & 271 & 97 & $35[28 ; 42]$ & $72[63 ; 83]$ & $90[78 ; 102]$ & $81[71 ; 92]$ & $75[66 ; 86]$ \\
\hline Cervix* & 17307 & 2208 & $12[12 ; 13]$ & $45[44 ; 46]$ & $75[74 ; 76]$ & $79[79 ; 81]$ & $88[87 ; 90]$ \\
\hline CNS/Liquor & 95 & 76 & $80[62 ; 98]$ & $102[82 ; 123]$ & $110[89 ; 132]$ & $93[75 ; 113]$ & $108[88 ; 129]$ \\
\hline Effusion & 487 & 327 & $64[58 ; 72]$ & $95[86 ; 104]$ & $94[86 ; 104]$ & $91[83 ; 100]$ & $91[82 ; 99]$ \\
\hline Lung FNA & 33 & 19 & $54[30 ; 79]$ & $79[49 ; 109]$ & $93[60 ; 128]$ & $96[62 ; 131]$ & $103[68 ; 138]$ \\
\hline Lung/Bronchus exfoliative & 432 & 212 & $47[41 ; 53]$ & $82[74 ; 91]$ & $93[84 ; 103]$ & $88[79 ; 97]$ & $88[79 ; 97]$ \\
\hline Lymph node & 729 & 458 & $62[57 ; 68]$ & $87[81 ; 94]$ & $101[94 ; 109]$ & $95[88 ; 102]$ & $96[89 ; 103]$ \\
\hline Pancreas & 87 & 79 & $89[70 ; 110]$ & $95[75 ; 116]$ & $94[73 ; 116]$ & $86[67 ; 105]$ & $101[81 ; 122]$ \\
\hline Salivary gland & 84 & 32 & $38[25 ; 52]$ & $78[60 ; 97]$ & $110[87 ; 133]$ & $114[91 ; 137]$ & $111[88 ; 133]$ \\
\hline Thyroid & 288 & 111 & $38[31 ; 64]$ & $101[90 ; 113]$ & $105[93 ; 117]$ & $101[90 ; 113]$ & $98[87 ; 109]$ \\
\hline Urine & 1034 & 586 & $54[50 ; 59]$ & $99[93 ; 106]$ & $105[99 ; 112]$ & $99[93 ; 106]$ & $104[98 ; 110]$ \\
\hline
\end{tabular}

Legend to table 2: *tissues with national screening programme. Red boxes show situations where the confidence interval of the ratio of measured and expected does not contain $100 \%$ and is considered statistically significantly different. The red number shows a ratio of less than $85 \%$, which might be clinically significant.

In most areas (central nervous system (CNS), lung fine needle aspiration (FNA), salivary gland, thyroid and urine; Table 2) numbers recovered in period 2 and were within expected limits for the rest of the year. Numbers of cervix cytology remained below expected throughout the year. Numbers of lymph node and 
salivary gland cytology did not recover until period 3. For breast cytology, exfoliative cytology of bronchus/lung and for effusion specimens a second dip was seen in periods 4-5 (Table 2).

For most areas the decline in benign diagnoses was stronger than the decline in malignant diagnoses during the lockdown dip of period 1 (Table 3). However, for breast cytology and effusion specimens the number of malignant diagnoses decreased relatively stronger than the number of benign diagnoses. For breast cytology there was a decline in malignant diagnoses in all periods $(74 \%$ in period $1 ; 23-43 \%$ in period 2-5).

Table 3. Ratio of observed average numbers of cytology examinations per week in 2020 versus 2019 for benign and malignant diagnosis according to tissue type during the 5 periods examined.

\begin{tabular}{|c|c|c|c|c|c|c|c|c|c|c|}
\hline \multirow[b]{2}{*}{ Tissue type } & \multicolumn{2}{|c|}{ P1 } & \multicolumn{2}{|c|}{ P2 } & \multicolumn{2}{|c|}{ P3 } & \multicolumn{2}{|c|}{ P4 } & \multicolumn{2}{|c|}{ PS } \\
\hline & Benisn. & Malismant & Benisn & Malizantint & Benisn & Matienant & Benign & Malignant & Benign & Maliznant \\
\hline Breast & $41[29 ; 54]$ & $26[13 ; 40]$ & $78[59 ; 79]$ & $77[46 ; 109]$ & $100(76 ; 124)$ & $57[34 ; 80]$ & 95 [71;118] & $74[44 ; 103]$ & $87 \mid 67 ; 108\}$ & $70[42,99]$ \\
\hline Cervix & $7[7 ; 8]$ & $24[17 ; 32]$ & $23[22 ; 24]$ & $28[20 ; 36]$ & $77[75,80]$ & $119 \mid 96 ; 143\}$ & 83 [80;85] & $93[74 ; 111]$ & $92[90 ; 95]$ & $106[86 ; 125]$ \\
\hline CNS/Liquar & $80[53 ; 107]$ & na & $106[71 ; 140]$ & na & $112(77 ; 147)$ & na & $\mid 91[63 ; 120]$ & na & $103[71 ; 134]$ & na \\
\hline Effusian & $61[50 ; 71]$ & $56[40 ; 73]$ & $95 \mid 79 ; 110]$ & $114(82 ; 145)$ & $95 \mid 79 ; 111]$ & $105(76 ; 134]$ & $108[90 ; 126]$ & $96[68 ; 123]$ & 88 [74;102] & $108|77 ; 139|$ \\
\hline Lung FNA & $50[12,89]$ & na & $60[22 ; 98]$ & na & 61 [15;107] & na & $52[16,29]$ & na & 89 |31;148] & na \\
\hline Lung/Bronchus e: & $44[36 ; 53]$ & $66[41 ; 91]$ & $78[65 ; 91]$ & 127 [85;170] & $83[69,96]$ & $104[71 ; 138]$ & $86 \mid 72 ; 100)$ & $104[70 ; 138]$ & $89[74 ; 104]$ & $88[58 ; 117]$ \\
\hline Lymph node & $61[51 ; 72]$ & $70[55 ; 85]$ & $95[80 ; 110$ & $106[86 ; 127]$ & $108 \mid 91 ; 124]$ & $109[88 ; 129$ & $\mid 103$ [87;119] & $96[78 ; 115]$ & $110 \mid 94 ; 127]$ & $100 \mid 80 ; 119]$ \\
\hline Pancreas & $64[26 ; 102]$ & $108 ; 50 ; 105]$ & $100[38 ; 162]$ & $100 \mid 42 ; 158\}$ & $86[33 ; 139]$ & $105[42 ; 167]$ & $82[31 ; 133]$ & $109[46 ; 172\}$ & $114[47 ; 181]$ & $113[51 ; 174]$ \\
\hline Sal ivary gland & $41[20 ; 62]$ & na & $74|41 ; 107|$ & na & $100|62 ; 138|$ & na & 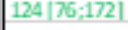 & na & $110|68 ; 153|$ & na \\
\hline Thyraid & $32[22 ; 42]$ & na & $104[80 ; 128]$ & na & $103|79 ; 127|$ & na & $96|74 ; 117|$ & na & $104[81 ; 127]$ & na \\
\hline Urine & $49[44 ; 55]$ & $63[41 ; 85]$ & | 101 [91; 111$]$ & $110|77 ; 143|$ & | $104|93 ; 114|$ & $108|75 ; 141|$ & $92[84 ; 101]$ & $108 \mid 74 ; 141]$ & | 101 |91;110| & $98 \mid 08 ; 128]$ \\
\hline
\end{tabular}

Legend to table 3: Red boxes show situations where the confidence interval of the ratio of observed numbers in 2020 versus 2019 do not contain $100 \%$ and are considered statistically significantly different. Bold underlined numbers show the situations where the relative decrease in malignant specimens is larger than for benign specimens. The red and green numbers show a ratio of less than $85 \%$ or more than $115 \%$. For numbers of cytology examinations per week, all specimens, benign and malignant diagnoses, see supplementary table 1. na = not available (less than 20 specimens per week)

Although there was no significant increase in total specimen numbers suggesting a catch-up, numbers of malignant exfoliative lung cytology in period 2 , malignant cervix cytology in period 3 , and for benign salivary gland cytology in period 4 showed an increase of more than $15 \%$ (Table 3 ).

\section{Histology}

\section{General trends for histologic specimens}

For histology, the largest decrease was observed during the first lockdown for all tissues, except for lymph node, pancreas and placenta (Table 4).

The sharpest lockdown dip was seen for specimens from the skin, gallbladder (Table 4), head and neck, soft tissue and upper and lower gastrointestinal tract (29\%-35\% of expected). 
The maximal decrease was much less in the next periods with a maximal decrease up to $71 \%$ of expected. Total numbers remained below expected throughout the year for breast, female genital tract, lung and skin. Numbers from the lower gastrointestinal tract remained below expected until period 5 .

\section{Table 4. Expected versus measured numbers of histology examinations per week according to tissue type during the 5 periods examined.}

\begin{tabular}{|c|c|c|c|c|c|c|c|}
\hline Tissue type & $\begin{array}{c}\text { expected } \\
\text { P1 }\end{array}$ & $\begin{array}{c}\text { measured } \\
\text { P1 }\end{array}$ & $\begin{array}{c}\text { meas/exp } \\
{[95 \% \text { d] } \mathrm{P} 1}\end{array}$ & $\begin{array}{c}\text { meas/exp } \\
{[95 \% \text { Cl] P2 }}\end{array}$ & $\begin{array}{l}\text { meas/exp } \\
{[95 \% \text { d] P3 }}\end{array}$ & $\begin{array}{l}\text { meas/exp } \\
{[95 \% \mathrm{cl}] \mathrm{P} 4}\end{array}$ & $\begin{array}{l}\text { meas/exp } \\
{[95 \% \text { d] P5 }}\end{array}$ \\
\hline Appendix & 340 & 266 & $74[66 ; 84]$ & $108[91 ; 119]$ & $105[94 ; 116]$ & $102[92 ; 113]$ & $104[93 ; 115]$ \\
\hline Bone marrow & 299 & 165 & $54[46 ; 62]$ & $88[77 ; 98]$ & $94[83 ; 106]$ & $83[73 ; 93]$ & $92[81 ; 103]$ \\
\hline Breast* & 1816 & 1103 & $58[55 ; 62]$ & $71[67 ; 75]$ & $85[80 ; 89]$ & $84[79 ; 88]$ & $88[84 ; 92]$ \\
\hline CNS & 124 & 95 & $77[62 ; 93]$ & $98[81 ; 116]$ & $96[78 ; 115]$ & $100[82 ; 118]$ & $79[64 ; 94]$ \\
\hline Female genital tract & 3225 & 1635 & $50[48 ; 53]$ & $79[76 ; 82]$ & $89[86 ; 93]$ & $92[88 ; 95]$ & $91[88 ; 94]$ \\
\hline Gallbladder & 342 & 106 & $29[23 ; 34]$ & $101[91 ; 111]$ & $114[102 ; 127]$ & $76[67 ; 85]$ & $81[72 ; 91]$ \\
\hline Head and Neck & 966 & 302 & $30[27 ; 33]$ & $89[84 ; 95]$ & $94[87 ; 100]$ & $93[87 ; 99]$ & $94[88 ; 100]$ \\
\hline Kidney & 180 & 132 & $71[59 ; 83]$ & $74[62 ; 87]$ & $95[80 ; 111]$ & $82[69 ; 96]$ & $96[82 ; 110]$ \\
\hline Liver & 240 & 189 & $78[67 ; 90]$ & $90[78 ; 102]$ & $97[84 ; 110]$ & $86[75 ; 98]$ & $96[84 ; 108]$ \\
\hline Lower GI tract* & 8282 & 3147 & $36[35 ; 37]$ & $73[71 ; 74]$ & $89[87 ; 91]$ & $95[93 ; 97]$ & $99[97 ; 101]$ \\
\hline Lung & 521 & 399 & $77[69 ; 84]$ & $79[72 ; 68]$ & $91[82 ; 99]$ & $91[83 ; 99]$ & $89[81 ; 97]$ \\
\hline Lymph node & 1200 & 1183 & $98[93 ; 104]$ & $76[71 ; 81]$ & $92[86-98]$ & $93[87 ; 98]$ & $95[89 ; 100]$ \\
\hline Pancreas & 41 & 37 & $93[63 ; 122]$ & $83[55 ; 111]$ & $83[55 ; 111]$ & $95[65 ; 125]$ & $91[64 ; 119]$ \\
\hline Placenta & 216 & 191 & $89[76 ; 101]$ & $84[72 ; 96]$ & $98[85 ; 111]$ & $97[83 ; 110]$ & $96[83 ; 109]$ \\
\hline Prostate & 780 & 512 & $61[56 ; 66]$ & $87[80 ; 84]$ & $98[90 ; 105]$ & $93[87 ; 100]$ & $96[90 ; 103]$ \\
\hline Skin & 12917 & 3674 & $29[28 ; 30]$ & $82[80 ; 93]$ & $96[94 ; 97]$ & $91[89 ; 93]$ & $93[92 ; 95]$ \\
\hline Soft tissue & 689 & 259 & $37[33 ; 42]$ & $84[77 ; 90]$ & $102[93 ; 110]$ & $86[80 ; 93]$ & $87[80 ; 93]$ \\
\hline Thyroid/adrenal & 121 & 64 & $51[38 ; 63]$ & $98[80 ; 115]$ & $98[78 ; 118]$ & $81[66 ; 97]$ & $88[72 ; 104]$ \\
\hline UpperGI tract & 2965 & 1180 & $38[36 ; 40]$ & $95[91 ; 98]$ & $96[92 ; 100]$ & $91[87 ; 94]$ & $93[90 ; 97]$ \\
\hline Urinary tract & 478 & 439 & $85[77 ; 93]$ & $87[79 ; 95]$ & $94[85 ; 103]$ & $100[91 ; 109]$ & $103[94 ; 113]$ \\
\hline
\end{tabular}

Legend to table 4: *tissues with national screening programme. Red and green boxes show situations where the confidence interval of the ratio of measured and expected does not contain $100 \%$ and is considered statistically significantly different. The red numbers show a ratio of less than $85 \%$, which might be clinically significant.

Numbers of appendiceal specimens recovered in period 2 and remained at expected levels during the rest of the year.

In other areas an initial recovery was seen in period 2 (CNS, gallbladder, liver, thyroid/adrenal gland) or period 3 (bone marrow, breast, head and neck, kidney) with a slighter drop during the second lockdown, mainly in period 4 (14-24\% drop in period 4 vs $22-71 \%$ drop in period 1$)$, but for some tissues also in period 5 (breast, gallbladder) or in period 5 only (CNS). For urinary tract and prostate, a recovery did not occur before period 3 , but numbers remained within expected limits in period 4 and 5 .

Although lymph node did not show a lockdown dip in period 1, numbers dropped significantly below expected in period 2, 3 and 4. 
The only statistically significant catch-up in histology numbers was seen for gallbladder in period 3 (114\%).

\section{Biopsy versus resection and benign versus malignant}

In the first lock down period, the number of benign diagnoses dropped for most tissues relatively more than the number of malignant diagnoses (Table 5), except for lymph node samples for which no significant drop was seen for benign diagnoses in period 1 nor for malignant diagnoses in any period.

Table 5. Ratio of observed average numbers per week of histology examinations in 2020 versus 2019 for biopsies, resections, benign and malignant specimens according to tissue type in week 13 - week 16, during first lockdown.

\begin{tabular}{|c|c|c|c|c|c|c|c|c|}
\hline Tlssue Type & Blopsy & Resection & Benlgn & Mal Ignant & Blopsy Benlgn & $\begin{array}{c}\text { Resectlon } \\
\text { Benlgn }\end{array}$ & $\begin{array}{c}\text { Blopsy } \\
\text { Mallgnant }\end{array}$ & $\begin{array}{l}\text { Resectlon } \\
\text { Mallgnant }\end{array}$ \\
\hline Appendlx & na & $77[65,90]$ & $76[63 ; 88]$ & na & na & $77[65,90]$ & na & na \\
\hline Bone marrow & $54[43 ; 66]$ & na & $50[34,67]$ & $63[44 ; 81]$ & $50[34,67]$ & na & $63[44 ; 81]$ & na \\
\hline Breast & $40[35 ; 45]$ & $75[67 ; 82]$ & $32[27 ; 37]$ & $76[69 ; 83]$ & $3[30 ; 44]$ & $26[19 ; 32]$ & $42[35 ; 49]$ & $105[92 ; 117]$ \\
\hline CN5 & na & $80[50 ; 109]$ & $57[23,90]$ & $90[50 ; 130]$ & na & $58[21,94]$ & na & $90[44 ; 136]$ \\
\hline Female genltal tract & $41[37 ; 45]$ & $53[48 ; 57]$ & $39[36 ; 42]$ & $85[72 ; 97]$ & $30[27 ; 33]$ & $41[36 ; 45]$ & $65[49,82]$ & $97[79 ; 114]$ \\
\hline Gallbladbler & na & $25[20 ; 30]$ & $25[19 ; 30]$ & na & $36[31 ; 41]$ & $25[19 ; 30]$ & na & na \\
\hline Head and Neck & $31[25 ; 37]$ & $12[8 ; 15]$ & $19[15 ; 22]$ & $86[60 ; 111]$ & na & $13[10 ; 17]$ & $69[41 ; 97]$ & $110[62 ; 184]$ \\
\hline Kldhey & $60[40 ; 80]$ & $76[49 ; 103]$ & $54[35 ; 73]$ & $81[53 ; 110]$ & $25[19 ; 31]$ & na & na & $81[49 ; 114]$ \\
\hline Ulver & $70[52 ; 88]$ & $103[56 ; 150]$ & $56[34 ; 78]$ & $92[66 ; 118]$ & $54[33 ; 75]$ & na & $83[56 ; 111]$ & $120[56 ; 184]$ \\
\hline Lower Gl-tract & $30[28 ; 33]$ & $35[33 ; 36]$ & $30[28 ; 32]$ & $76[66 ; 87]$ & $54[31 ; 78]$ & $30[27 ; 33]$ & $62[48 ; 76]$ & $88[72 ; 104]$ \\
\hline Lung & $62[51 ; 73]$ & $83[62 ; 105]$ & $50[36,64]$ & $81[66,97]$ & $50[33,66]$ & $51[26 ; 76]$ & $71[54 ; 88]$ & $103[70 ; 135]$ \\
\hline Lymph node & $75[59 ; 91]$ & $98[99 ; 108]$ & $96[85 ; 106]$ & $93[80 ; 106]$ & $70[43,96]$ & $99[87 ; 110]$ & $79[57 ; 101]$ & $99[83 ; 115]$ \\
\hline Pancreas & na & $110[43 ; 177]$ & na & na & na & na & na & na \\
\hline Placenta & na & $88[71 ; 106]$ & $\approx[71 ; 106]$ & na & na & $\approx[71 ; 106]$ & na & na \\
\hline Prostate & $64[56 ; 72]$ & $35[27 ; 42]$ & $36[30 ; 42]$ & $73[62 ; 84]$ & $52[41,63]$ & $16[10 ; 22]$ & $74[61 ; 87]$ & $72[50,93]$ \\
\hline $5 \mathrm{kln}$ & $23[21 ; 21]$ & $32[31 ; 34]$ & $24[23 ; 26]$ & $34[32 ; 36]$ & $23[21 ; 25]$ & $25[24 ; 27]$ & $21[19,24]$ & $41[38 ; 44]$ \\
\hline Soft tlssue & $56[44 ; 69]$ & $18[14 ; 23]$ & $21[17 ; 26]$ & $75[54 ; 97]$ & $45[30 ; 59]$ & $13[9 ; 13]$ & $69[46 ; 91]$ & $105[41 ; 169]$ \\
\hline Thyrold/adrenal & na & $46[30,63]$ & $31[17 ; 45]$ & $105[43 ; 166]$ & $33[31 ; 36]$ & $32[17 ; 46]$ & na & $111[40 ; 182]$ \\
\hline Upper Gl-tract & $35[32 ; 37]$ & $54[40,67]$ & $34[31 ; 36]$ & $75[56 ; 93]$ & na & $44[29 ; 59]$ & $71[49 ; 93]$ & $81[48 ; 114]$ \\
\hline Urinary tract & $63[50 ; 77]$ & $86[72 ; 101]$ & $64[49 ; 79]$ & $85[70,99]$ & $62[44 ; 79]$ & $69[42,96]$ & $66[43 ; 89]$ & $92[74 ; 109]$ \\
\hline
\end{tabular}

Legend to table 5: Red boxes show situations where the confidence interval of the ratio of measured and expected does not contain $100 \%$ and is considered statistically significantly different. Red and green numbers show a ratio of less than $85 \%$ or more than $115 \%$, which might be clinically significant. For numbers of histology examinations per week, biopsies, resections, benign and malignant diagnoses, see supplementary table 2 .

Analogous tables for periods 2-5 are given in supplementary tables 3-6. na $=$ not available (less than 20 specimens per week)

A similar pattern was seen for biopsies versus resections, where biopsies dropped more severely in period 1 than resections, except for head and neck, prostate and soft tissue for which the drop in resections was larger. Resections with a malignant diagnosis were spared in period 1 (Table 5). 
A statistically significant decrease of numbers in other periods than the first lockdown period was seen in at least one other period for benign diagnoses of most tissues (Fig. 1 and supplementary tables $3-7$ ). A statistically significant reduction of malignant diagnoses in other periods than the first lockdown period was only seen for breast, lower GI-tract, female genital tract and prostate, mostly in period 2, immediately after the first lockdown. Only numbers of malignant breast diagnoses were affected in more periods (Fig. 1 and supplementary tables $3-7$ ).

The decrease during the second lockdown (periods 4 and 5) could for many tissues be attributed to a decrease in specimens with a benign diagnosis (Fig. 1 and supplementary tables 5 and 6).

A statistically significant increase of specimen numbers (catch-up) was only seen for malignant skin specimens, especially resections, in period 3 , between lockdowns (supplementary table 4 and Fig. 1) and for benign lower-GI tract resections in period 5 (supplementary table 6 and Fig. 1)

\section{Discussion}

In 2020 the world faced a new reality when it had to cope with the SARS-CoV-2 pandemic. Many aspects of people's lives were affected by the illness itself and the measures taken to restrain viral spread. Healthcare services struggled to find a balance between treating the large numbers of covid- 19 patients and continuing regular non-covid patientcare.

The number of examined pathology specimens is an indirect measure for a part of the healthcare provided. The changes in specimen numbers may help understand which areas of clinical care were affected most during the pandemic and are at risk to suffer long term effects. The Netherlands has a nationwide database containing all pathology reports since 1991 (PALGA), which creates an outstanding opportunity to study this impact and to explore which areas were affected most.

In line with the number of hospital admissions and number of persons dying from covid-19, the strongest decline in specimen numbers was observed during the first spike of the pandemic. The decrease in this period was very high (67\%), but total numbers remained below expected during the whole year (overall decrease of 18\%). A second dip during the second lockdown was seen for some tissue types and procedures, although much less prominent. Moreover, not all specimen types were affected equally.

During the first lockdown national screening programmes for colorectal carcinoma, breast carcinoma and cervical carcinoma were paused. This explains the huge decline in cytology specimens from cervix and breast ( $88 \%$ and $65 \%$ respectively) and the strong decrease in histological specimens from the lower gastrointestinal tract $(65 \%)$ in period 1 . Although screening was resumed after the first lockdown, cervical cytology numbers remained below expected levels throughout the year. Colorectal biopsies containing a malignancy returned to expected levels after period 1, but breast biopsies from malignant lesions were below expected in period 2 as well. Moreover, numbers of resected malignancies remained lower than expected for both lower gastrointestinal tract and breast in period 2 and 3 and period 2-4 respectively. 
Part of these numbers were previously reported by the Dutch Cancer Registry (Integraal Kankercentrum Nederland, IKNL), which reported a drop in the numbers of stage I colorectal carcinoma, early stages of breast cancer and breast carcinoma in situ due to the temporarily suspended screening programmes. Numbers of newly diagnosed patients returned to expected levels in autumn [6] [https://iknl.nl/covid19/covid-19-en-kanker-van-de-spijsverteringsorganen] [ https://iknl.nl/covid-19/covid-19-en-borstkanker]

The decline in resected malignancies from lower gastrointestinal tract, female genital tract and breast after period 1 might not only reflect a lower number of cancer diagnoses. It might be that a choice for other (neoadjuvant) treatment modalities like radiotherapy and/or chemotherapy was made more frequently under the given circumstances, thus postponing surgery and putting less strain on intensive care facilities [7]. However, a catch-up in numbers is not seen.

In the normal situation histology of the skin makes up the largest part of the diagnostic volume in Dutch pathology laboratories, but during the first lockdown numbers plummeted with $72 \%$. Although biopsies and resections from benign skin disease remained low, a slight catch-up (between 5-9\%) was seen for malignant skin disease after period 1. Skin care might belong to the clinical areas which are delayed relatively easily in times of crisis because many skin diseases are not or may not seem immediately lifethreatening. Moreover, patients might delay seeking care for lesions that do not cause severe symptoms $[8,9]$.

In contrast to the areas discussed above, other areas seem hardly affected by the pandemic. It is not surprising that placentas belong to this category, but remarkably numbers for pancreas, central nervous system (CNS) and liver remained relatively stable as well. Considering that diseases of these organs are often treated in specialised tertiary care centres, it raises the question whether their relatively stable numbers result from a conscious choice to prioritise the treatment of certain diseases, whether the stable numbers are caused by the severity of presenting symptoms or whether the way in which covid-19 patients were spread over the Dutch hospitals, dictated indirectly which non-covid patientcare could be continued.

Apart from the areas discussed above, a general observation is that the number of specimens containing a malignancy decreased relatively less than the number of specimens with benign disease, suggesting that a serious effort was made to continue cancer care as much as possible. This is supported by the fact that the number of resections for malignancies dropped less than the number of biopsies. The decline in biopsy numbers might, although partly attributed to the pause in screening programmes, also be due to people's reluctancy to seek medical care. The observation that cytology numbers were affected less than biopsy numbers might be explained by the slightly different role of cytology in the diagnostic process.

Catch-up in numbers after the first lock down dip was minimal. It was only seen for histology and the maximum was $17 \%$ (for benign resections of the colon). In all other instances in which some catch up was observed (e.g. resections of malignant skin lesions) the catch-up was less than $10 \%$. 
Because the pandemic put a strain on intensive care availability, this indirectly affected surgical capacity. A Dutch research group developed a model to predict the health impact of postponing surgical procedures for both benign and malignant disease by estimating the disability-adjusted life-years per month of delay [10]. This model shows that 20 of the 23 surgical procedures for which a delay would have the strongest negative impact, were oncological. Our analyses show that surgery for malignant disease was relatively spared during the corona crisis, which seems a logical choice based on the data from the Gravesteijn study.

The situation for benign disease is more difficult to assess. Most of the surgical procedures for benign disease included in the study by Gravesteijn et al. do not produce pathology specimens. So similar studies/models for different procedures are needed to assess the impact of the decrease in benign specimens observed in our study, as in the study of Te Groen et al [11]. The procedures involved in the catch-up seen for benign resections of the lower Gl-tract in our study might be the follow-up of their results.

Although the PALGA-database covers pathology reports nationwide and many areas of patientcare, it obviously does not include all healthcare areas. Because the results of this study reflect the Dutch situation, it might in several respects be different from the situation in other countries. Moreover, for some categories specimen numbers were too small for meaningful analysis. Despite these limitations the results of this study highlight remarkable changes in patientcare during the corona crisis. The impact is yet unknown, but it raises important questions:

What is the consequence of the pause in national screening programmes? Will the experiences of the past year, with a decline (and thus at least partly delay) in the number of surgical interventions, lead to a shift in the use of different treatment modalities for certain diseases (e.g. chemoradiotherapy instead of surgery)? Will there be a worse outcome for patient with postponed cancer diagnosis and/or treatment? What is the impact on health and quality of life of delaying surgery (skin, soft tissue, breast, gallbladder, prostate) or biopsy diagnosis (colon) for benign disease? Should a new or continuing pandemic lead to different healthcare choices?

Together with studies on the health impact of postponing surgical procedures [10], the data presented here help to assess the consequences of the corona pandemic on (public) health and provide a starting point in the discussion on how to make the best choices in times of scarce healthcare resources, recognizing the impact of both benign and malignant disease on quality of life.

\section{Declarations}

Funding: not applicable

Conflicts of interest/Competing interests: the authors have no conflicts of interest or competing intersts 


\section{Authors' contributions}

MLF van Velthuysen: design, writing, analysis

S van Eeden: writing

S le Cessie PhD: analysis

M de Boer: design and clinical context

$H$ van Boven: design and clinical context

B Koomen: design and clinical context

F Roozekrans: design and clinical context

J Bart: design and clinical context

W Timens: design and clinical context

QJM Voorham: data generation, analysis

All authors read and approved the final manuscript

Ethics approval: not applicable

Consent to participate: not applicable

Consent for publication: not applicable

\section{References}

1. Masroor S. Collateral damage of COVID-19 pandemic: Delayed medical care. J Card Surg. 2020;35(6):1345-7.

2. Vigliar E, Cepurnaite R, Alcaraz-Mateos E, Ali SZ, Baloch ZW, Bellevicine C, Bongiovanni M, Botsun P, Bruzzese D, Bubendorf $L$, et al. Global impact of the COVID-19 pandemic on cytopathology practice: Results from an international survey of laboratories in 23 countries. Cancer Cytopathol. 2020;128(12):885-94.

3. Ferrara G, De Vincentiis L, Ambrosini-Spaltro A, Barbareschi M, Bertolini V, Contato E, Crivelli F, Feyles E, Mariani MP, Morelli L, et al. Cancer Diagnostic Delay in Northern and Central Italy During the 2020 Lockdown Due to the Coronavirus Disease 2019 Pandemic. Am J Clin Pathol. 2021;155(1):64-8. 
4. Casparie $M$, Tiebosch AT, Burger $G$, Blauwgeers $H$, van de Pol A, van Krieken JH, Meijer GA. Pathology databanking and biobanking in The Netherlands, a central role for PALGA, the nationwide histopathology and cytopathology data network and archive. Cell Oncol. 2007;29(1):19-24.

5. Amrhein V, Greenland S, McShane B. Scientists rise up against statistical significance. Nature. 2019;567(7748):305-7.

6. Dinmohamed AG, Cellamare M, Visser O, de Munck L, Elferink MAG, Westenend PJ, Wesseling J, Broeders MJM, Kuipers EJ, Merkx MAW, et al. The impact of the temporary suspension of national cancer screening programmes due to the COVID-19 epidemic on the diagnosis of breast and colorectal cancer in the Netherlands. J Hematol Oncol. 2020;13(1):147.

7. Rosenbaum L. The Untold Toll - The Pandemic's Effects on Patients without Covid-19. N Engl J Med. 2020;382(24):2368-71.

8. Andrew TW, Alrawi M, Lovat P. Reduction in skin cancer diagnoses in the UK during the COVID-19 pandemic. Clin Exp Dermatol. 2021;46(1):145-6.

9. Rich H, O'Neill T. Major fall in urgent skin cancer referrals during the COVID-19 outbreak. J Plast Reconstr Aesthet Surg. 2021;74(3):644-710.

10. Gravesteijn B. Minimizing Population Health Loss in Times of Scarce Surgical Capacity During the Coronavirus Disease 2019 Crisis and Beyond: A Modeling Study VALUE in HEALTH2021, 24(5).

11. Te Groen M, Derks MEW, Kuijpers C, Nagtegaal ID, Hoentjen F. Reduction in Inflammatory Bowel Disease Healthcare During the Coronavirus Disease 2019 Pandemic: A Nationwide Retrospective Cohort Study. Gastroenterology. 2021;160(3):935-7 e931.

\section{Figures}




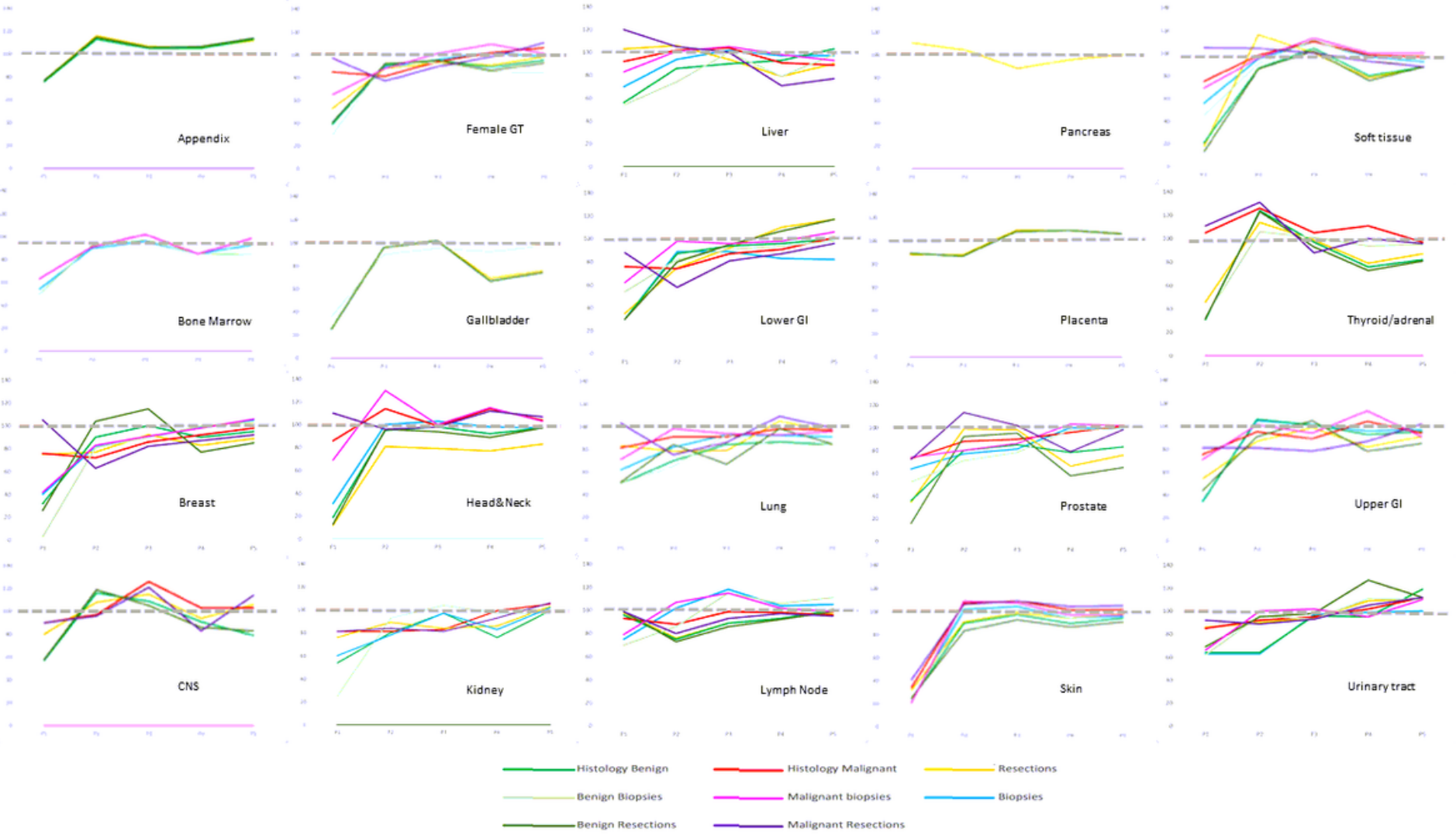

\section{Figure 1}

Ratio of observed average numbers per week of histology examinations in 2020 versus 2019 for biopsies, resections, benign and malignant specimens according to tissue type in all periods examined (period1period5). Legend to figure 1: grey dotted line shows $100 \%$ level. Green lines show benign samples, bright green are all benign samples, light green biopsies, dark green resections. Purple and red lines show malignant samples, bright red are all benign samples, light purple biopsies, dark purple resections. Yellow lines are all resections. Blue lines are all biopsies.

\section{Supplementary Files}

This is a list of supplementary files associated with this preprint. Click to download.

- Suplementarytables30052021.docx 